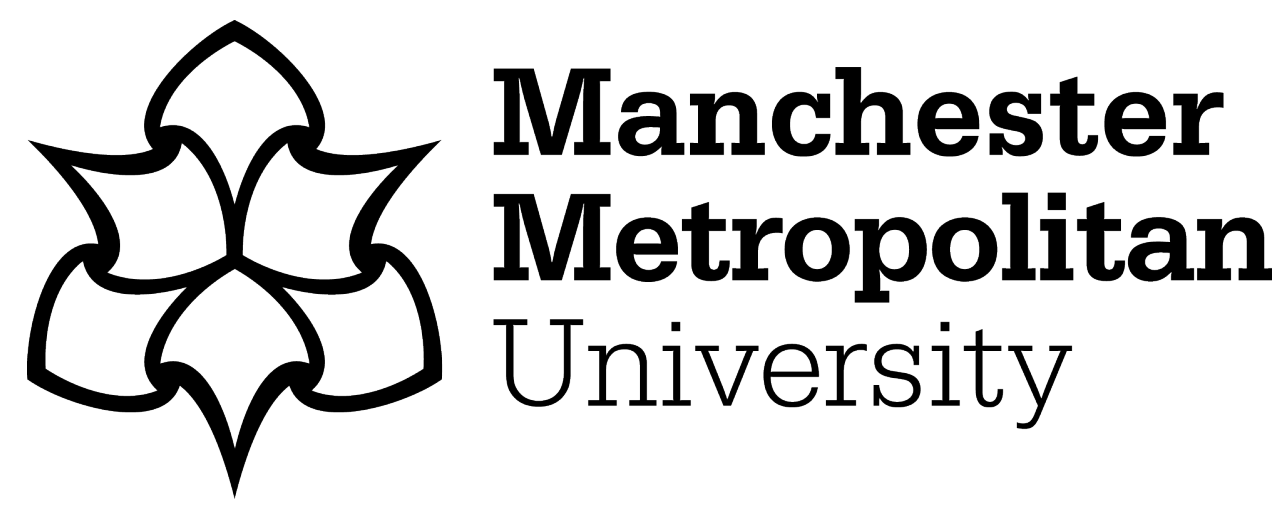

Jackson, D (2017) Can games help creative writing students to collaborate on story-writing tasks? International Journal of Game-Based Learning, 7 (3). pp. 38-50. ISSN 2155-6849

Downloaded from: https://e-space.mmu.ac.uk/622232/

Version: Published Version

Publisher: IGI Global

DOI: https://doi.org/10.4018/IJGBL.2017070104

Please cite the published version 


\title{
Can Games Help Creative Writing Students to Collaborate on Story-Writing Tasks?
}

David Jackson, Manchester Metropolitan University, Manchester School of Art, Manchester, England

\begin{abstract}
Story writing is a complex semantic and creative task, and the difficulty of managing it is made greater by attempting to write in collaboration with others. This complication can deter students from experimenting with collaboration before mastering their own practice in relative privacy. Such reticence is in spite of the fact that there are many clear benefits to collaboration. These include peer support and feedback for the student on their practice (Leach, 2014; Vygotsky, 1978), and the development of collaborative skills and experiences that are easily transferable to a range of creative contexts in future (Ravetz et al., 2013). Specially designed games have the potential to help to facilitate collaboration, by making the difficulty of telling a story as a group part of the game's challenge.
\end{abstract}

\section{KEYWORDS}

Collaborative Skills, Creative Collaboration, Creative Writing, Game Based Pedagogy, Story Telling, StoryWriting Games

\section{INTRODUCTION}

A playful approach to problems (Schell, 2008) inherent in gameplay can actively mitigate a sense of risk (Bateson, 2006) and mark the act of playing as a positive formative experience of collaboration. Limitations reduce task complexity too. Players have the opportunity to become familiar with each other's collaborative working styles in an environment controlled by the games rules. However, the quality of the text produced during play is important to the longer-term role of such games in creative writing classrooms. If games cannot produce meaningful stories it is unlikely that participants will wish to continue playing them at the cost of their normal creative practice.

This paper shares research from my $\mathrm{PhD}$ thesis showing how my specially designed digital games helped creative writing students collaborate more easily. It makes reference to a collective case study of play-testing sessions with degree-level participants where the majority had never collaborated on a creative writing project before. In the case study, students report that games do promote a sense of teamwork between them and other participants. They also provided opportunity for self-reflection in a way that is relatively unique to collaborative practice (John-Steiner, 2000). Finally, a summary of the feedback from an expert panel on the quality of stories shows the effect of game rules on the quality and meaningfulness of the story created during the games in class.

\section{Project Method Summary}

In order to explore the possibilities of game-based story writing, I developed two web-based games that formed an online platform Storyjacker (www.storyjacker.net). These were produced via an iterative design methodology which involved cyclical phases of software development and user 
testing, primarily with higher education students. Design was also informed by a literature review and analysis of four other online writing platforms.

Creative writing students were tasked with playtesting two different online games (Figure 1), Game 1 and Game 2, in small groups of three or four. Game 1 (Twisted) begins by offering Player 1 a narrative outline and other cues designed to inspire them to write a story. Player 1 then types out the start of the story based on these cues. At the end of their turn they are instructed to add a complication (a twist) for the next player, such as switch perspective. The next player (Player 2) must continue the story and respond to the twist (i.e. they must switch perspective within the narrative), before finally setting their own twist (e.g. Figure 2). The game continues until one of the players elects for the next turn to finish the story.

In Game 2 (Bamboo), the first player is offered inspirational prompts to begin a story. Then, following Player One's turn, Players Two and Three offer alternative continuations of the plot. Player One then chooses one plotline and discards the other (see Figure 3). Player One must continue the

Figure 1. Gameplay structures of Game 1 and Game 2

\section{Game 1}

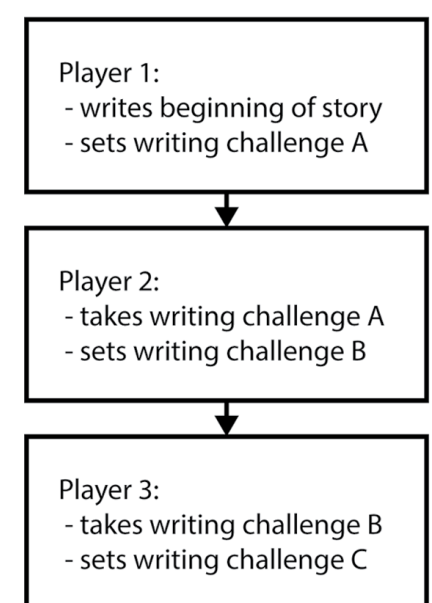

\section{Game 2}

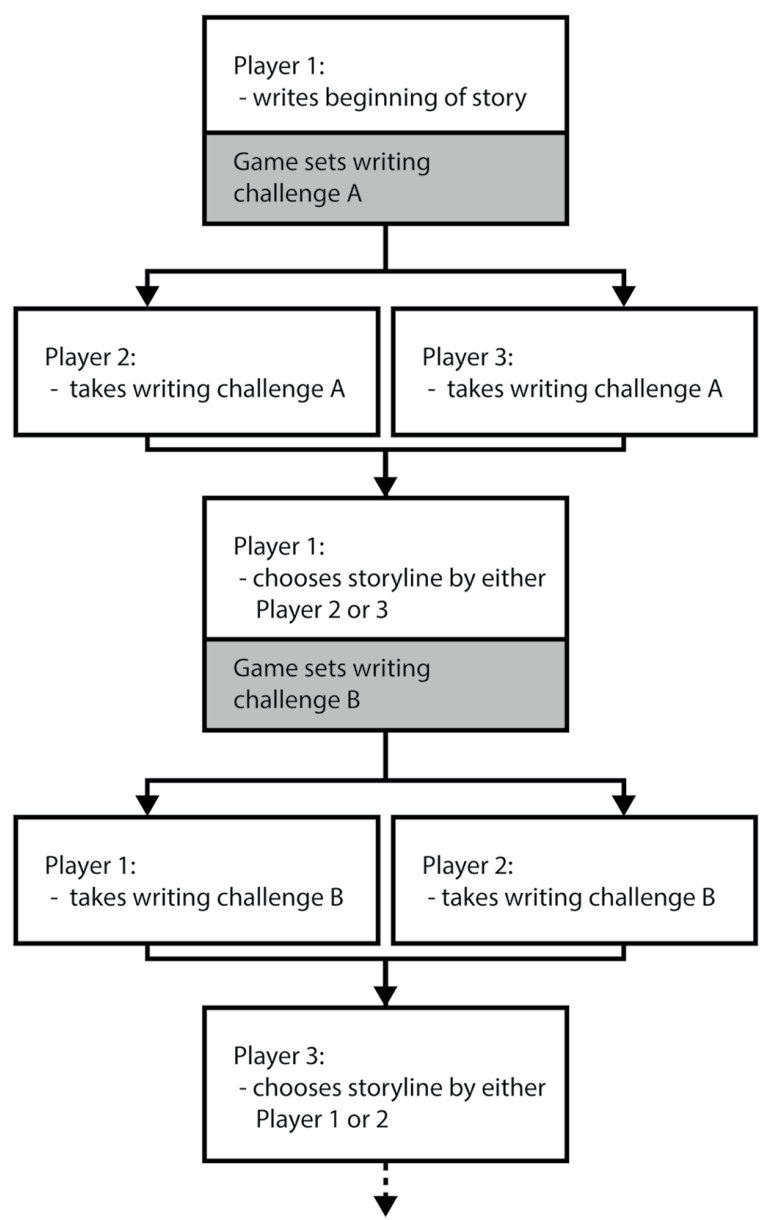


Figure 2. Game 1 player writes new chapter in response to challenge

1. Write the next chapter with this twist: Lose the protagonist

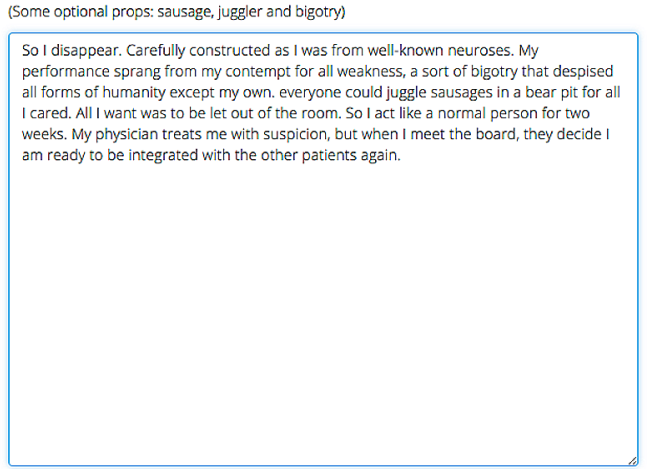

415 characters left

2. Set the twist and befuddle the next writer

$$
\begin{aligned}
& \text { Switch perspective } \\
& \text { End the story } \\
& \text { Change tense } \\
& \text { Write only using dialogue } \\
& \text { Write using words with only one syllable } \\
& \text { Use all suggested props } \\
& \text { Use one long continuous sentence. } \\
& \text { Write in one-word sentences } \\
& \text { Lose the protagonist } \\
& \text { Use only questions } \\
& \text { Remove all the 't's } \\
& \text { Set a different twist hert }
\end{aligned}
$$

PREVIOUS CHAPTER:

They let them take me. My family locked their coors the men in suits drag me away. Not even Mummy c didnt ike me- neither d col, so they woulon't hav all the Marminy would. used to dream about how: evernbodys hearss, Mus. She would swing a big: she can't, That's hecause Dadidy and Collet them to trapped somewhere. My room is pretty. It's pink an on the walls. But I don't like pretty things. My room that's 'cause we were poor and Mummy and Daddy we still had to stay forever. Ust like Daddy pretend

Figure 3. Game 2 offers the player two alternative story segment to choose from

\section{hamboo Back to main site Start new game Read Bamboo stories Logged in as David-}

STORY PROGRESS Q

-

PLAYERS

\section{Surf and return}

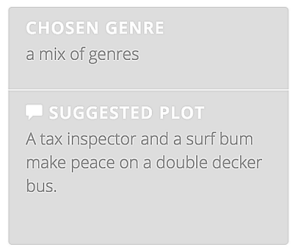

After the awkward what-do-you-do conversations which put the embryonic friendship between the two men to the test, conversation was saved by the discovery of a shared passion:

\section{DAVID JOHN JACKSON, DECIDE WHAT GOES NEXT.}

(N.B. BOTH PLAYERS WERE CHALLENGED TO USE ONLY WORDS THAT END IN A VOWEL.) salsa dancing. Blurted out by Simon, the surfer, a kind of fall on your sword gesture that was meant to show he was as capable of being nerdy as a tax inspector. hula! Who made these two a duo? No one. Written by John

Choose 
plotline they have chosen and Player Two writes their alternative. The winner of this second round is chosen by Player Three. Player Three and Player One will write next, with Player Two choosing, and so on. The game continues for ten turns at which point writers must finish the story.

Following the design phase, a selection of the stories that had been produced during Storyjacker testing were then rated and commented on by an expert reading panel, made up of four creative writing academics from higher education institutes (HEI) and two literary industry professionals. The panel's ratings and comments inform a final analysis of the value of stories produced by the games in an HEI creative writing classroom setting.

\section{Defining Creative Collaboration}

In order to understand the nature of the challenge faced by students learning to collaborate on creative writing projects it is necessary to define creative collaboration, especially as it occurs in a learning context. If we accept the definition put forward by Moran and John-Steiner in Collaborative Creativity (2004), creative collaboration is the highest standard of working together in a creative context, involving an intricate balance of collaborator qualities to 'realise a shared vision of something new and useful' (p. 12). It is such a shared vision, they say, that differentiates it from cooperation, which simply implies 'the constraint of a shared purpose'; or working together, which only implies 'coordination of effort'. However, the definition of collaboration is problematic and impractical. It suggests that proof of collaboration is that it produces something new and useful, or that collaborators have a shared vision of something new and useful. This suggests that creative interactions that start out speculatively or playfully and end variously with useful and original, or silly and derivative works are only creative collaborations in the case of the former. In the case study, students describe a sense of collaboration in writing together regardless of outcome. Gabrielle Ivinson offers a less restrictive definition, stating that the art student 'sitting silently drawing in a life drawing class' is involved in collaboration with the artistic community that invented life drawing, her art school and even her family (Ivinson, 2004, p. 96). If this generous conceptualisation of collaboration is correct, what is it we talk about when we discuss collaboration within this arrangement; where does collaboration start and finish when three creative writing students collaborate together to play a writing game?

In fact, creative writing classrooms may be particularly encouraging of collaboration. Heather Leach in The Road to Somewhere (2014) outlines the collaborative creative culture that creative writing pedagogy relies on. Whilst engaged on a creative writing course one is reliant on others for 'ideas, feedback, time to write and motivation, but above all... permission to be a writer' (p. 90). All those in a given group share these dependencies: writers offer their practical support 'in exchange for the same' from peers (Leach, 2014, p. 92). Whilst it is not necessarily the case that every glib comment on a student's work by another constitutes active collaboration, it is still clear that students studying and working within a creative writing group share the 'joint passionate interest in a new problem, art form or societal challenge' that John-Steiner considers 'crucial to collaborative success' (John-Steiner, 2000, p. 189).

Certainly, when testing Storyjacker, collaborative games played in university classrooms and other learning spaces succeeded in fostering productive collaboration with creative writing students after games played or convened online had failed. In addition to the collaborative contract described by Leach, players enjoyed communicating with each other. In fact, Maarten De Laat and Vic Lally (2004) use a model of gradual group development over the lifetime of a collaboration that begins with dialogue and familiarisation and finishes with a complicated synthesis of viewpoints. During the project playtests, in cases where writers were already more familiar with working with each other, serious debate was easier and where writers were less familiar, casual and humorous group conversation on broad topics where there was common ground prevailed. This all supports the notion that elements outside of collaborative intent should be considered influential when defining the extent to which it is collaboration. 


\section{Learning Outcomes of Collaboration}

Previous research pinpoints many of the important characteristics that can be consistently observed in the work of creative collaborators. For example, Amanda Ravetz, Alice Kettle and Helen Felcey, in their book Collaboration through Craft (2013) describe the actions of any creative craft as a balance of certainty and risk. Collaboration, state the authors, is often an undermining force in the balance between these two, and can cause a work to fail either by precipitating 'an entropic restriction of ideas and forms' through a tendency towards too much certitude, or poor-quality work through an indulgence in too much uncertainty (Ravetz, Kettle \& Felcey, 2013, pp. 5-6). During the project, evidence of the former was documented in complaints from expert reading panellists about overreliance on clichéd imagery in some stories; and the latter can be found in the form of a breakdown of coherence in some stories (evidenced in feedback from the reading panel below). In collaboration, makers must transpose their normal considerations of risk and care into new contexts, 'involving friction that may go beyond the maker's existing skill set' (Ravetz, Kettle \& Felcey, 2013, p. 6). In other words, the maker who goes into collaboration with a skillset related to the task must learn to adapt their creative knowledge and extend it.

In some contexts, such as forms of copywriting, soap scriptwriting and journalism, collaboration is often the norm. However, as Ravetz et al point out, for other writing practitioners 'collaboration is a temporary excursion and the learning that results from collaboration is something to be used back within their established practice' (Ravetz, Kettle \& Felcey, 2013, p. 13). Indeed, it may be in part the temporality of collaborative partnerships that imbues them with a sense of exploration and examination. Its differences also inform what we learn: collaboration 'impinges on' notions of individuality that we usually take for granted. The writer-as-maker 'who is dependent on possession [ownership of work]' but 'paradoxically also dependent on others for their self-constitution' through collaboration becomes open to her own inherent 'fluidity and relationality' (2014 p. 9). In other words, the collaboration that is at work in every act of learning that the individual undertakes, the mediation by others of everything from our first word to the acquisition of advanced techniques for storytelling, is made more explicit during collaboration. This might be because it mirrors the formative role of collaboration in early learning, documented Lev Vygotsky. He observed that group learning precedes individual learning in child development, specifically as group play:

[A] child first becomes able to subordinate her behaviour to rules in group play and only later does voluntary self-regulation of behaviour arise as an internal function. (Vygotsky, 1978, p. 90)

For Vygotsky, group play is a fundamental activity in the process of learning. In play, rules are enacted collectively until they are internalised by each of the players.

\section{Games and the Creative Writing Pedagogy}

Writing games as exercises are a common feature of creative writing classes and workshops. In The Cambridge Introduction to Creative Writing, David Morley explains the reason why writing games are so important to creative writing as a learning method: they are a way to develop and maintain writing skills by simulating normal creative writing processes in a focused and concise manner:

Writing creatively can feel a little like working out logistical, even mathematical, challenges. Writing games provide this elegant calculus in taut form. (Morley, 2007, p. xiv)

In Morley's definition games are a way of simulating 'the real thing', a way of practising for an important piece. The complexity of creating an extended work of creative writing requires that it be produced 'in stages, as passages, scenes and stanzas and each stage requires several drafts. Writing games clone this process, and are often true to the natural rhythm of literary production' (Morley, 
2007, p. xiv); the form of writing games, often short and focused, is not at odds with the process of writing longer work because these longer works are often produced through a series of short and focused bursts too. Morley positions the games in the place that they were situated in my own creative writing education: as a practice for the real piece of work to come.

In Hazel Smith's The Writing Experiment she explains her higher education teaching of creative writing as 'systematic and based on step-by-step strategies'. The premise is similar to that of the Storyjacker games: 'you do not have to have an idea to start writing, but you can generate ideas by manipulating words' (Smith, 2005, p. 3). Playing writing games is rearticulated here as 'engaging with language-based strategies' which when absorbed deeply enough can render all words 'triggers for writing'. This power of creative generation she notes, stems from the fact that words are polysemic: they can conjure up many associations at once. Smith offers a number of word association activities that can help the writer produce new and interesting combinations and as a result new ideas and directions of travel in writing.

\section{Challenges of Creating Collaborative Story-Writing Games}

When considering story-writing games, what complicates this notion of fun as a productive motivational strategy is the addition of a difficult-to-define literary product and a collaborativecreative process. Any game that excites players to write meaningful fiction must surely combine two motivational elements: motivation to play the game as well as the motivation to create meaningful stories. Story game designer James Wallis suggests motivation to create stories emanates from a natural desire for resolution; 'your imagination sees a pattern of events and resolves it into a story' (2007, p. 69). The balancing of this story-making motivation with normal game motivation requires a game which is 'both fun and creates a satisfying story' (Wallis, 2007, p. 70); it requires what he terms 'story/game balance' (p. 73).

If, as Wallis comments, this balance is 'not easy to achieve' (ibid.), it may well be to do with the effect that competition has on our ability to be creative. A study by Teresa M. Amabile (1983) concluded that the nature of what motivates writers has a direct effect on their creativity. The test used individuals who identified themselves as 'actively involved in creative writing' (Amabile, 1983, p. 393). Writers were asked to write a poem before and after a task asking them to rank reasons for writing from a predetermined list. The study found that if a writer in the test was given a list and asked to rank extrinsic reasons for writing, for example 'you know that many of the best jobs available require good writing skills' (Amabile, 1983, p. 396), then they were more likely to write a lower quality second poem, compared to a control group. Those who were told to focus on and order intrinsic reasons, 'you feel relaxed when writing' or 'you like to play with words' (Amabile, 1983, p. 396), had slightly better results than the control group, who had unaffected motivations. It might be inferred by this that the role of a game that aims to get the best out of a creative writer is to heighten this intrinsic motivation for writing and reading, rather than attempting to reward output or closely tie performance to outcome.

These studies suggest that in situations where students are attempting to be creative, their output is very sensitive to the feedback of peers and the design of their environment. As the Storyjacker tests indicate, surroundings and the social configuration of play can have as much effect on writers as the game itself. Whilst fun can be heightened by creating a satisfying challenge or an objective it is important that that objective is not extrinsic to the creative writer's core reasons for writing, or it will inhibit and negatively affect the quality of their output.

\section{CASE STUDY FINDINGS}

During the project three groups were observed using the platform: creative writing students, students on other creative arts courses and published authors. Over 60 playtesters, mainly comprising HEI students, produced more than 50 stories. However, this paper focuses on a collective case study 
represented by the creative writing student (CWS) group. These students were from various cohorts and represented both postgraduate and undergraduate courses on two separate university campuses. The case study documents both online and class based testing. Feedback and reactions to the games were captured via survey and observational methods, as well through the stories the students produced during the lessons.

\section{Problems with Distance Play Testing and Creative Writers}

During the early phase of the project, it proved very difficult to engage with creative writing students as playtesters. Early prototypes were designed to be played online with remote players. Two pilot playtesting plans with creative writing students failed and it was challenging to gain any insight into the motivations of non-participants. However, rather than attributing this lack of engagement to the students testing the work, I put this problem down to a fundamental flaw in my testing methodology: I had begun testing with remote participants at a stage when Tracy Fullerton in A Playcentric Approach to Creating Innovative Games (2014) recommends playing with 'confidants' whilst present so that the designer can 'explain the game to them to begin with... because the prototype will likely be incomplete' (p. 250). Playing with a diverse and remote target audience is reserved by Fullerton for the fourth and final refinement stage (Fullerton, 2014, p. 252). Jeremy Gibson is similar in his description of an expanding circle of playtesters, from yourself, to trusted friends outwards. The outermost ring of this playtesting group is online testing. He advises that the game 'should be in beta phase before you attempt this' (Gibson, 2014, p. 150) because 'there is little or no accountability for actions or statements' online Gibson, (2014, p. 147). Adoption of classroom-based workshops provided better insight of what could be causing problems for remote testers. Those who attended the first sessions were motivated in part by meeting up and socialising with other writers. This notion is reinforced by observations by Heather Leach (2014) about creative writing pedagogy in the literature.

In tests, the Storyjacker games only worked well with relatively high levels of support provided by a facilitator. In all facilitated classroom environments, students worked happily in groups. Players preferred this supportive environment: when offered a choice for a follow-up session, groups expressed a preference for class- rather than web-based activities. This ultimately supported the findings from studies that show that collaboration cannot occur where there is not the opportunity to establish a shared language and aims, to foster trust in an open and committed process (Storey 2004). In addition, trends of participation online show that it is always a minority that participate actively in creative activities online (Nielsen, 2006; Goodier, 2012), so that large numbers (far larger than typical class sizes) are required in order to guarantee enough self-motivated participation.

There was an expectation that the creative writing classroom and cultures surrounding it would offer effective support for the kind of experimental creative writing practices Storyjacker exhibited. This appeared to be the case: students responded well to the platform and understood and appreciated the game as a process for making stories. Creative writing students generally saw the application of the polysemic and random response methods as a way to practise their writing in the manner of the writing games description by Morley (2007) in the literature.

However, whereas the idea of writing using prompts and other game-like devices were familiar to them, the idea of collaborating on a piece of writing was not. In fact, the creative writing student play testers involved in the project typically had little or no experience of collaboration on creative writing projects. In a sample group, fifteen of the nineteen testers had never collaborated on a creative writing project before and considered the idea of it novel and rewarding. In their feedback was evidence of two trends in experience. Some reported that the games promoted a sense of creative teamwork they had not encountered before as creative writers and was fun:

Good fun to collaborate with others.

Working collaboratively meant our ideas bounced off one another, which sparked inspiration.

Working with like-minded people helped to create an enjoyable experience. 
In other students, the games encouraged a more introspective effect, leading them to reflect on discoveries about their own working practices in feedback.

[R]eally interesting to help see what people think of my characters.

It was fun to see all the ways that people respond to and expand on your ideas.

I enjoyed being challenged as a writer and also seeing my own piece evolve.

In this case, personal insights by students into their own work came about as an effect of collaborating with others on their writing. In the creative collaboration case studies of Vera JohnSteiner (2000) she noted that a 'long-term creative collaboration can act as a mirror...: a chance to understand one's habits, styles, working methods and beliefs through comparison and contrast with one's collaborator' (p. 189). It appears that even in these short-term collaborations, similar selfreflection can be achieved: not in spite of collaboration but because of it.

\section{Gameplay and Collaborative Story-Writing}

\section{Humour, Play, and the Mitigation of Risk in Collaboration}

The Storyjacker games helped people collaborate on story-writing tasks. The amount of fun players reported having was consistently high across all groups and over the course of the testing certain conclusions could be drawn about the elements that made the games entertaining. Humour was often present in both the stories that participants wrote in the form of jokes and farcical plot structures, and evident in their reporting of their own approach. Participants saw this as a way of limiting their exposure to being judged. As in other creativity studies (Cade, 1982; Holmes, 2007), humour did not seem to distract from the task. Instead it fostered an easy relationship between players and allowed the groups to enjoy what they were doing together.

On two reported occasions, humorous narrative strategies by players produced inappropriate stories, involving derogatory depictions of groups such as the elderly. What is a glib, sarcastic strategy for comedy in a relatively quick-fire game such as Game 2, where surprising and outrageous plot twists thrive, does not always translate well for story readers. Readers are used to considered texts published only after authors have had the opportunity to consider their jokes and any offense they might cause. There was no clear relationship between humour and the marks of the panellists (there is some well-judged humour in all of the highest marked stories). However, texts they reported as displaying an unsavoury humour were marked punitively, with low scores in all categories.

When people played Game 2, there was a complementary strategy to humour reported that also helped to navigate collaborative vulnerabilities: the player whose go it was to choose would pick the player who had been overlooked one or more times in the recent rounds, even if they were not the best option. The use of Bateson's concept of metacommunication goes some way to explain this phenomenon. Metacommunication in play denotes a sense of distance from any serious function to demonstrate that this is play, in order to mitigate threat (Bateson, 2006, p. 318). A non-game collaboration might demand only the best option regardless of collaborator and every choice made by the players would be a negative assessment of the loser's writing ability. Instead players opted to foster a low-threat collaboration through their gestures of playfulness. The distanced attitude denoted by laughter could also be characterised as a way to communicate a sense of play, in the way that Bateson describes.

\section{Reading Panel Feedback on the Value of the Stories to Readers}

During the evaluation stage of the project, the reading panel reviewed a selection of the stories written by the games. In the feedback that followed two responses could be identified.

Two points of view polarised feedback and were explicitly referenced by three of the panelists (Table 1), nearly always in juxtaposition: 


\section{Ghost Gorilla}

\begin{abstract}
Two bikers and their pet monkey are riding their bikes when one of their bikes suddenly break down. Seeking refuge they break into a monastery, angering a nun who tells them that the building is haunted, by the ghost of a Raz Ma Eem's pet Gorilla.
\end{abstract}

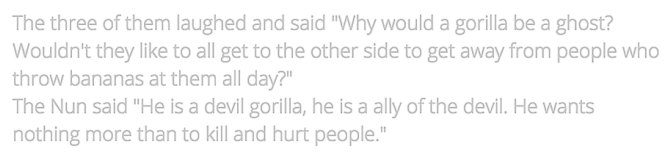

nothing more than to kill and hurt people."

\begin{abstract}
While the other two guys slept Spats, the monkey, sat boredly for a few minutes looking around the dark room. Suddenly a loud animal roar echoed throughout the bedroom. Spats pulled at Jimmy's hand before he was pushed away. Spats suddenly felt hot breath above him and hot white spit dropping on him
\end{abstract}

Spat looked up to see a demonic, white gorilla with ruby red eyes. The Gorilla smiled and grabbed Spat, and charged out of

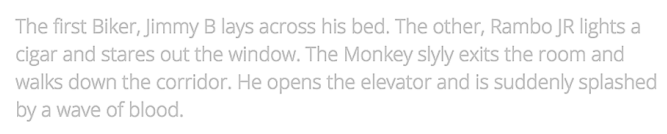
by a wave of blood.

Figure 5. Prompts pop up when the reader moves their cursor over the text

Two bikers and their pet monkey are riding their bikes when
one of their bikes suddenly break down. Seeking refuge they
break into a mo Namil was challenged to describe s them that the
building is haun using senses other than sight or m's pet Gorilla.
sound

The bikers, being 'hard men' in their own eyes, shrug off what the nun says and inform her they are taking a room.
The three of them laughed and said "Why would a gorilla be a ghost?
Wouldn't they like to all get to the other side to get away from people who

- The Writer-as-Reader (Referred to as the Reader-Writer, or Writer): In all cases, the writeras-reader could find something valuable either in the taking part in these games as exercises, as satisfying their interest in storytelling, or to inspire more experimental approaches to their own practice. Especially through the leftover fragments in the Game 2 presentation, Panelist 3 sees the potentiality of worlds that we might write ourselves into, through, out of. This is not only reading, but thinking of writing whilst reading.

- The Story Reader (Referred to Variously as 'the "Lay" Reader, Non-Writer or Reader): The story reader takes a more absolute position: for them there was a success imperative, which dictated that the stories should succeed in making sense and in offering a satisfying ending. From this second reader's perspective, it was felt that stories mainly failed to hit the mark. As well as the texts often failing to succeed as stories, those presentational elements that made reading the game stories interesting to the writer-as-reader, such as in-game challenge labels and comparative texts (Figure 4 and Figure 5) weakened the experience of the story. 


\begin{tabular}{|c|c|}
\hline Writer-as-reader response & Story reader response \\
\hline $\begin{array}{l}\text { '....as a workshop exercise I could see it yielding real } \\
\text { benefits to the writers' (Panellist 1) }\end{array}$ & $\begin{array}{l}\text { '...as a reader it was a rather forced, derivative and } \\
\text { introspective imitation of the kinds of collaborative/online } \\
\text { authorship that are already occurring' (Panellist 1) }\end{array}$ \\
\hline $\begin{array}{l}\text { '...I found this interesting as someone who is interested in } \\
\text { the craft of storytelling and writing...' (Panelist 2) }\end{array}$ & $\begin{array}{l}\text { '...it might weaken the experience of the story for a 'lay' } \\
\text { reader (Panelist 2) }\end{array}$ \\
\hline $\begin{array}{l}\text { 'As a writer I'm interested in the "possibilities" and don't } \\
\text { view this story as either a work in progress or a finished } \\
\text { collaborative narrative - rather it inspires me to be more } \\
\text { experimental with my own approach to story-building.' } \\
\text { (Panelist 3) }\end{array}$ & $\begin{array}{l}\text { 'How much it might affect how a non-writer would } \\
\text { respond is difficult to imagine.' (Panelist 3) }\end{array}$ \\
\hline $\begin{array}{l}\text { 'As a reader-writer, these tales enable us to glimpse } \\
\text { fragments of worlds that we might write ourselves into, } \\
\text { through, out of. Even if we never choose to develop any } \\
\text { of these alternative approaches in any great detail, the } \\
\text { fact of having experimented with them brings a new } \\
\text { understanding to our own processes.' (Panelist } 3 \text { ) }\end{array}$ & $\begin{array}{l}\text { 'As a "reader" there is the success imperative - does the } \\
\text { story make sense, is the viewpoint consistent, is the ending } \\
\text { satisfying?' (Panelist } 3 \text { ) }\end{array}$ \\
\hline $\begin{array}{l}\text { 'I think this struck me as a valuable workshop/craft/ } \\
\text { discipline exercise for the writers... as I say it has many } \\
\text { other benefits which I could imagine making it well worth } \\
\text { a writer's while to engage with.' (Panelist 1) }\end{array}$ & $\begin{array}{l}\text { '...from a reader's point of view, I find the stories mainly } \\
\text { failed to hit the mark, and I thought the transparent, } \\
\text { painstakingly accountable collaborative process mainly } \\
\text { obstructed my engagement as a reader...' (Panelist 1) }\end{array}$ \\
\hline
\end{tabular}

For those panelists that used this terminology, the extent to which they took up these positions, either as a typical story reader or as writer-as-reader generally informed their scores and response to the text: the lowest scorer, Panelist 1 , explicitly positioned themselves as a story reader, ('for me as a reader' and 'from a reader's point of view, I find...'). The highest scorer, Panelist 2, explicitly positioned themselves as a writer or reader-writer, ('As a writer I' $m$ interested in...' and 'As a readerwriter, these tales enable us to...').

Both positions find ample agreement in Roland Barthes' $S / Z$ (1990). In it, he identifies the readerly and the writerly as two types of text, as two ways of understanding text. The readerly experience is a product of the usual divorce 'between the producer of the text and its user' (1990, p. 3). In the readerly model, the reader is 'plunged into a kind of idleness -he is intransitive; he is, in short, serious: ... instead of gaining access to... the pleasure of writing, he is left with no more than the poor freedom either to accept or reject the text' (1990, p. 4); as noted above, for panelists as story-readers, stories either hit the mark or did not. In contrast the writerly text 'is ourselves writing, before the infinite play of the world... is traversed, intersected, stopped, plasticized by some singular system' (1990, p. 5). Barthes notion of literary appreciation involves embodying the writer to bring the possibilities of the text to life: any 'typology of texts' can 'be linked only to a practice... of writing' (1990, p. 6). Evidence of gameplay in the presentation of Storyjacker texts not only promotes a more game-like appreciation of the story; it also seems to clarify the link to the practice of writing by documenting each stage of the written process.

The findings from reader and player feedback point to overlapping narratives in game stories: distinct elements beyond the story itself that draw out and document the process of writing for participating students:

- Evidence of a Performance: Part of what obstructs the game text's transition to becoming a draft of a story is the residue left by its own performance: that self-conscious element (Norwood, 2010) that tells of its live origins. In classroom writing games, this narrative element tended to describe the awkward performance of writing as gameplay. It can be witnessed in the overlapping 
Figure 6. An example of both self-conscious prose and typographic errors

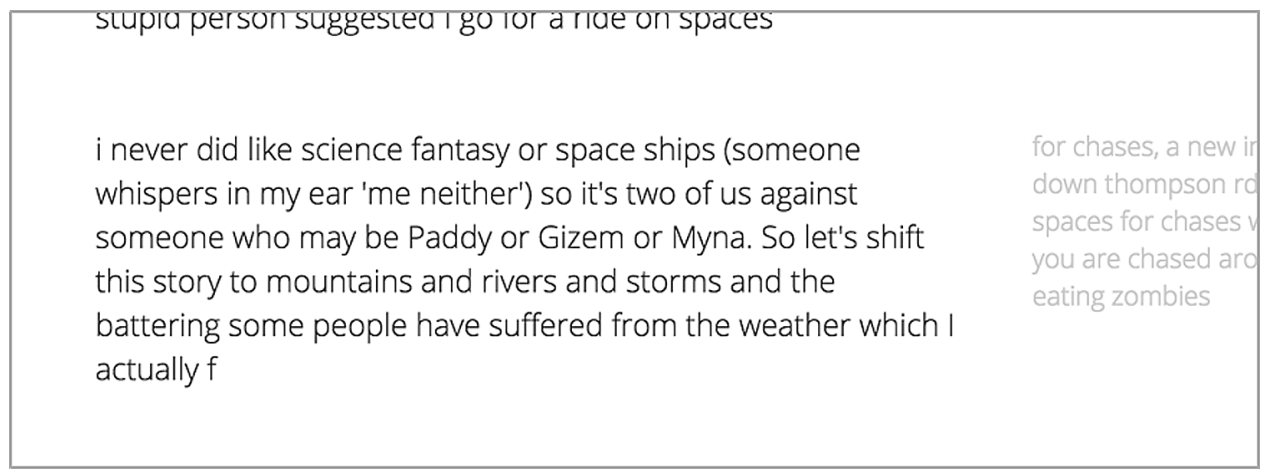

of story events with the events involved in constructing the story (someone whispers in my ear in Figure 6 is an actual event during play). This is a relatively exclusive reference, which primarily targets its audience at time of writing: the other players. Traditionally, fiction readers as an audience are separated from the writer by industrial process, fixing them as other, an external target for the readerly text (Barthes, 1990). This is not the case in Storyjacker games. Students are physically close to each other so can often read what is written prior to publication and just after publication. They are by turn then its writers, further blurring the reader-writer boundary.

- Evidence of the Game: Whilst switching between writing and reading roles occurs, no doubt, within any writing process, i.e. I write for a moment and then read back what I have written, the Storyjacker multiplayer game externalises and draws apart the normal read-write processes of composition as a series of marked events structured as play: separate moves by opposing players. This is denoted most obviously by challenge-text markers (Figure 5) that describe the type of play and players involved in producing the specific episode. The narrative of play that these text elements inform, in turn affects the story text. The challenge message in Figure 5 not only tells me about the writing event, it also provides a cipher to decode the story text that accompanies it. As well as positioning the writer in the text, therefore allowing easier access to a writerly appreciation of the text (Barthes, 1990), these records of the game also elicit in the reader a sense of debate and divergence more typical to games and their post-mortems, such as in Alan Aycock's observations about tournament chess (1983) when 'numerous previously silent lines of play... are spoken' (Aycock, 1993, p. 21). In this way, the student as reader plays out many possible other storylines from the one that occurred, exhausting the story 'along several seams'. In the Game 2, evidence of story segments rejected in the game sometimes led to comments about preferred alternative plotlines by the reading panel.

- Evidence of Single-Phase Development: During the tests, students treated the stories produced as final pieces. There is also no interface in the platform that allows writers to edit the work after submission. This means that games often feature typographic errors (e.g. the unfinished word ' $f$ ' in Figure 6). By the same degree, it offers unedited access to the first drafts of experienced and novice writers alike; something that reading panellists thought to be useful as a point of reflection for creative writing students.

The meaningfulness of any story text is potentially expanded or changed by including the description of its creation: new meanings are found by a framing of the text with surrounding texts or paratexts, as explained by Steven Jones in The Meaning of Video Games (2008). What makes these game-based story texts different, however, is the permeation of the game narrative paratext within the story text itself. It offers students and staff reviewing the game stories a sense of that story as a document of the creative process and as a tool for learning about creative writing and collaboration. 


\section{CONCLUSION}

This study underlines the importance of collaborative working in the creative writing classroom and the role games have to play in introducing collaborative strategies. The Storyjacker games reviewed in this paper offered creative writing student participants an introductory context for writing collaboratively that they found fun to engage with. In addition, students reported specific learning outcomes related to their collaborations. Some participants reported that they had a positive first experience of writing as part of a team (despite being in competition with each other in the game). Others were able to reflect on the way that fellow students incorporated their writing into ongoing narratives. This gave them new perspectives with which to develop their creative writing practice.

There are also benefits for students who read through the games, without necessarily playing them. The playful presentation of text does not provide an uninterrupted story reading experience but it does offer fresh perspectives on the writing process that can potentially stimulate and inspire student writers. The evidence that a story could have been written another way or that it was only written in a certain way because of game-based restrictions reportedly encourages the reader to reflect on the process and event of writing rather than simply the quality of the story. This offers novel insights into story writing that cannot so easily occur in normal writing practice. The stories that are produced can highlight, for example, the importance of redrafting in creating narrative coherence and the awesome divergence of endings that fellow storywriters envisage from the same story beginning.

It is not clear whether there is an ongoing benefit for students to engage with these types of multiplayer writing games, once they progress into more meaningful types of collaboration (or return to more individualistic writing practices with lessons learnt). This is especially the case given that readers as readers do not appear to wholly enjoy the texts produced by games such as those tested but rather see them as fertile grounds for writerly contemplation. Further work is needed to clarify the role of games in higher education creative writing classrooms and the collaborative projects that could follow. 


\section{REFERENCES}

Amabile, T. M. (1983). Motivation and Creativity: Effects of Motivational Orientation on Creative Writers. Proceedings of the Annual Convention of the American Psychological Association, Anaheim, USA.

Aycock, A. (1993). Derrida/Fort-Da: Deconstructing Play. Postmodern Culture, 3(2).

Barthes, R. (1975). The Pleasure of the Text. Farrar, Straus and Giroux.

Barthes, R. (1990). S/Z. Blackwell.

Bateson, G. (2006). A Theory of Play and Fantasy. In K. Salen \& E. Zimmerman (Eds.), The Game Design Reader: A Rules of Play Anthology. Cambridge, Mass.: MIT Press.

Cade, B. W. (1982). Humour and creativity. Journal of Family Therapy, 4(1), 35-42. doi:10.1046/j..1982.00575.x Fullerton, T. (2008). Game Design Workshop: A Playcentric Approach to Creating Innovative Games. CRC Press.

Gibson, J. (2014). Introduction to Game Design, Prototyping, and Development: From Concept to Playable Game with Unity and C. Addison-Wesley Professional.

Holmes, J. (2007). Making Humour Work: Creativity on the Job. Applied Linguistics, 28(4), 518-537. doi:10.1093/ applin/amm048

John-Steiner, V. (2000). Creative Collaboration. Oxford University Press.

Leach, H. (2004). Writing Together: Groups and Workshops. In R. Graham, H. Newall, H. Leach, \& J. Singleton (Eds.), The Road to Somewhere: A Creative Writing Companion. Basingstoke, Hampshire, New York: Palgrave Macmillan.

Moran, S., \& John-Steiner, V. (2004). How collaboration in creative work impacts identity and motivation. In D. Miell \& K. Littleton (Eds.), Collaborative Creativity: Contemporary Perspectives (pp. 11-25). London: Free Association Books.

Morley, D. (2007). The Cambridge Introduction to Creative Writing. Cambridge Introductions to Literature. Cambridge: Cambridge University Press. doi:10.1017/CBO9780511803024

Norwood, T. (2010). The Writing of Performance. In R.L. Clapham (Ed.), (W)reading Performance Writing: A Guide. Live Art Development Agency (LADA Study Room Guides).

Ravetz, A., Kettle, A., \& Felcey, H. (2013). Collaboration through Craft. A\&C Black.

Schell, J. (2008). The Art of Game Design: A Book of Lenses. Taylor \& Francis Group.

Smith, H. (2005). The Writing Experiment: Strategies for Innovative Creative Writing. Allen \& Unwin.

Storey, H., \& Joubert, M. M. (2004). The Emotional Dance of Creative Collaboration. In D. Miell \& K. Littleton (Eds.), Collaborative Creativity: Contemporary Perspectives. London: Free Association Books.

Vygotsky, L. S. (1978). Mind in society: The development of higher psychological processes. Cambridge, MA: Harvard University Press.

Wallis, J. (2007). Making Games That Make Stories. In P. Harrigan \& N. Wardrip-Fruin (Eds.), Second Person: Role-playing and Story in Games and Playable Media. Massachusetts: MIT Press. 